\title{
PENGARUH PERJANJIAN VERSAILLES YANG DISUSUN SEPIHAK OLEH SEKUTU TERHADAP JERMAN TAHUN 1919
}

\author{
Afiani Arofatul Zidah \\ Universitas Negeri Malang \\ afiani.arofatul.1907316@students.um.ac.id
}

\begin{abstract}
Abstrak
Perang dunia I terjadi pada tahun 1914-1918 yang melibatkan kekuatan besar antara Blok Sekutu dengan Blok Sentral. Setelah 4 tahun berperang Jerman yang merupakan blok sentral mengalami kekalahan melawan Sekutu. Pada tahun 1919 diadakan perjanjian damai antara negara-negara sekutu dengan Jerman. Perjanjian tersebut adalah perjanjian Versailles dimana Jerman menerima tanggung jawab penuh atas terjadinya perang. Perjanjian Versailles ini ternyata dibuat sepihak oleh Sekutu untuk menghukum Jerman. Jerman tidak diberikan kesempatan untuk bernegoisasi. Sekutu memberikan ketentuan hukuman kepada Jerman seperti militer,ekonomi dan kewilayahan. Dampak dari perjanjian Versailles sangat di rasakan oleh Jerman karena mengalami krisis ekonomi yang parah. Penelitian ini menggunakan metode kualitatif. Metode kualitatif digunakan untuk memperhatikan suatu peristiwa. Dalam menggunakan metode kualitatif ini penulis mengumpulkan data yang akan diteliti kemudian mendeskripsikan secara detail dari data-data yang diperoleh melalui jurnal,dokumen, maupun buku. Metode kualitatif ini menggunakan teknis analisis yaitu dengan mengkaji suatu permasalahan dengan lebih mendalam. Tujuan artikel ini untuk mengetahui isi perjanjian Versailles, tokoh dari perjanjian Versailles, dampak perjanjian Versailles, dan pelanggaran perjanjian Versailles.
\end{abstract}

Kata Kunci: perjanjian versailles, perang dunia I, sekutu, Jerman

\begin{abstract}
The world war that occurred in 1914-1918 involved large powers between the Allied Powers and the Central Powers. After 4 years of war, Germany, which was the central bloc, suffered a defeat against the Allies. In 1919 there was a peace agreement between the allied countries and Germany. The agreement is the Versailles agreement in which Germany accepts full responsibility for the events of the war. The Allies made the Versailles Treaty unilaterally to punish Germany. Germany was not given the opportunity to negotiate. The Allies provided Germany with provisions for protection such as military, economic and territorial. The impact of the Versailles agreement was felt by Germany because of the severe economic crisis. This study uses a qualitative method. Qualitative methods are used to pay attention to events. In using this qualitative method the writer collects the data to be examined and then describes in detail the data obtained through journals, documents, and books. The qualitative method uses technical analysis, namely by examining a problem in more depth. The purpose of this article is to examine the contents of the Versailles Treaty, the figures of the Versailles Treaty, the impact of the Versailles Treaty, and the Versailles Treaty.
\end{abstract}

Keywords: treaty of versailles, world war I, allies, Germany 


\section{PENDAHULUAN}

Perang adalah sesuatu yang tidak dapat dihindari. Hampir semua bangsa di dunia pernah dibasahi oleh darah akibat peperangan. Perang adalah konflik yang menggunakan persenjataan dan disengaja untuk memperebutkan kepentingan. Tidak semua negara yang berperang berhasil mencapai tujuan yang diinginkan. Bahkan ada beberapa negara yang hancur akibat peperangan. Resiko yang akan di hadapi saat berperang sangatlah berat karena harus mengorbankan segala hal (Sarsito, 2009). Terjadinya perang pasti ada pemicunya, begitu pula dengan Perang Dunia I. Semua pihak yang terlibat perang tentunya ingin menjadi pemenang. Kekalahan dianggap sebagai pecundang di mata dunia, apalagi yang terlibat didalam peperangan adalah kaum bangsawan Eropa (raja) yang memiliki otoritas mutlak (kekuasaan). Perang dunia I terjadi pada tahun 1914 sampai 1918 yang merupakan sejarah kelam bagi dunia terutama Eropa. Perang dunia I ini melibatkan kekuatan besar antara Blok Sekutu (Prancis, Inggris, Rusia, dan lainnya) dengan Blok Sentral (Jerman, Austria-Hongaria, Kekaisaran Ottonam, Bulgaria). Awalnya Pemerintah Raja Edward VII takut jika kehadiran Kekaisaran Jerman menjadi raksasa di kawasan Eropa. Jerman mengalami kemajuan ekonomi, teknologi dan kebangkitan politik. Kaisar Jerman Wilhelm II menerapkan kebijakan internasional yang bertujuan untuk menjadikan negaranya sebagai poros dunia. Jerman sebagai kekuatan baru dianggap sebagai ancaman oleh Inggris.Sehingga Inggris ingin mendisintegrasi kekuatan Jerman dengan cara mengisolasi. Kemudian Raja Edward VII berhasil mengikat Rusia dan Prancis. Karena kemungkinan Prancis masih memiliki dendam terhadap Jerman lantaran pernah di kalahkan dalam seri perang Franco-Prussion tahun 1870. Selain itu Inggris juga memprovokasi Prancis terkait wilayah Alsace-Lorainne yang diambil Jerman. Pada tahun 1914 Jerman dan Inggris bersaing untuk meningkatkan militernya terutama angkatan laut. Terbukti dengan meningkatnya jumlah kapal perang dan jumlah pasukan tempur. Persaingan di bidang militer inilah yang mendorong terjadinya perang. Selain itu adanya imperialisme dimana negaranegara di Eropa bersaing untuk mendapatkan daerah kekuasaan di Afrika dan beberapa bagian di Asia, sehingga terjadi ketegangan (Arifian, 2020)

Terjadinya perang dunia I dimulai saat Serbia berambisi mendirikan negara baru Yugoslavia dengan menyatukan Serbia, Kroasia, Slovenia, Kosovo,Makedonia dan Bosnia. Namun sayangnya Bosnia-Hezegorvina telah dikuasai oleh Austria-Hongaria. Sehingga ambisi Serbia untuk mendirikan negara baru ini terancam gagal, kemudian seorang pemuda dari Serbia bernama Gavrilo Principe nekat membunuh putra mahkota Austria, Franz Ferdinand dan istrinya. Sehingga pada tanggal 28 Juli 1914 Austria-Hongaria menyatakan perang terhadap Serbia. Negara-negara waktu itu membuat aliansi pertahanan bersama dengan negara tetangga. 
Aliansi tersebut adalah Rusia dengan Serbia, Jerman dengan Austria Hongaria, Prancis dengan Rusia, Inggris dengan Prancis. Dalam aliansi ini ada perjanjian yaitu jika satu negara diserang maka sekutunya harus membela. Sehingga adanya aliansi pertahanan bersama tersebut maka Rusia mendukung Serbia, sedangkan Jerman mendukung Austria-Hongaria. Inggris dan Prancis ikut menyatakan perang karena hal ini merupakan kesempatan untuk mengalahkan Jerman. Sehingga pada tanggal 5 Agustus 1914, lima negara besar di Eropa yaitu Austria,Jerman berperang melawan Rusia,Prancis,dan Inggris. Kemudian Turki ikut serta bergabung ke Blok Sentral untuk melawan Rusia. Pada tahun 1915 Jerman berhasil menguasai Serbia dan Montenegro, selain itu Jerman juga berhasil menyerang dan menenggelamkan kapal dagang Sekutu. Tiga kapal dagang tersebut ternyata milik Amerika Serikat sehingga Amerika melibatkan diri untuk ikut berperang (Putra, 2018). Perang disebabkan karena perebutan wilayah, dalam konsepsi hukum internasional telah diatur tentang bagaimana cara suatu negara bisa memperoleh maupun kehilangan wilayah (Bangun, 2017).

Setelah berperang kurang lebih empat tahun Blok Sentral mengalami kekalahan. Kekalahan Blok sentral ini diakibatkan karena pertama, Blok sekutu mempunyai anggota yang lebih banyak, masuknya AS menambah kekuatan Blok Sekutu. Kedua, Perpecahan Blok Sentral dimana Italia yang awalnya adalah anggota Blok Sentral berpindah ke Blok Sekutu karena menginginkan daerah yang dikuasai Austria. Ketiga, terjadi pemberontakan rakyat di negara anggota Blok Sentral karena sudah tidak ingin berperang dan tidak mendukung pemerintah. Sehingga peperangan di menangkan oleh pihak Sekutu. Setelah perang dunia berakhir kedua pihak mengadakan perjanjian. Muncul berbagai perjanjian yaitu perjanjian Versailles antara sekutu dengan Jerman, perjanjian St Germain antara sekutu dengan Austria, perjanjian Neuilly antara pihak sekutu dengan Bulgaria, perjanjian Trianon antara sekutu dengan Hongaria, dan perjanjian Sevres antara Sekutu dengan Turki. Perjanjian-perjanjian ini menyertai berahkirnya perang dunia I.

Dari penjelasan di atas tentang penyebab dan proses terjadinya perang dunia I, penulis ingin membahas lebih lanjut tentang akhir dari kekalahan Jerman yang kemudian diadakan perjanjian antara Sekutu dengan Jerman yaitu, perjanjian Versailles. Tujuan penulisan ini adalah untuk mengetahui terbentuknya perjanjian Versailles untuk Jerman, mengetahui isi perjanjian Versailles yang dibuat sepihak oleh sekutu untuk Jerman, mengetahui para tokoh yang merancang perjanjian Versailles, mengetahui pengaruh perjanjian Versailles terhadap Jerman, serta pelanggaran yang dilakukan Jerman untuk keluar dari perjanjian Versailles. 


\section{METODE PENELITIAN}

Penulis menggunakan metode kualitatif dalam menyusun artikel ini dalam memperoleh data. Dalam menggunakan metode kualitatif ini penulis mengumpulkan data yang akan diteliti kemudian mendeskripsikan secara detail dari data-data yang diperoleh melalui jurnal, dokumen, maupun buku. Metode kualitatif ini menggunakan teknis analisis dengan mengkaji suatu permasalahan dengan lebih mendalam. Langkah pertama penulis menentukan topik yang akan diteliti. Dalam menentukan topik ini penulis mencari sumber data baik dari buku maupun sumber yang lain. Sumber data ini dicari melalui berbagai sumber referensi mengenai Perang Dunia I di artikel, jurnal, dan e-book. Kemudian yang kedua adalah tahap pengumpulan semua referensi yang cocok dengan topik penelitian yaitu, perjanjian Versailles. Sumber yang relevan dicari melalui internet maupun e-book. Ketiga, penulis melakukan catatan yang penting mengenai perjanjian Versailles dari sumber-sumber yang sudah dikumpulkan. Keempat, setelah mencatat hal-hal yang penting penulis mengevaluasi sumber yang ditemukan menganalisis data agar mendapatkan data yang aktual. Kelima, penulis mulai menyusun sumber-sumber dan menyajikan dalam bentuk satu artikel utuh.

\section{HASIL DAN PEMBAHASAN}

\section{Terbentuknya Perjanjian Versailles}

Militer Jerman yang didesain oleh Erich ludendorff berhasil dikalahkan oleh Sekutu. Jerman telah kehilangan prajurit lebih dari 600.000 dan gagal melakukan terobosan dalam menentukan arah kemenangan. Pada tanggal 26 September 1918 Sekutu melakukan serangan kepada Jerman sebagai pukulan telak. Serangan ini disebut Allied Grand Offensive. Pasukan Sekutu (Amerika, Prancis, dan Inggris) berhasil mencapai lini pertahanan utama Jerman (Hindenburg). Terjadi pertempuran sengit antara gabungan Sekutu dengan Jerman. Ribuan pasukan Jerman yang kelelahan,kelaparan, dengan semangat yang sudah kendur perlahan mulai menyerah. Pada tanggal 12 Agustus 1918 serangan Sekutu berakhir dan mengakibatkan 40.000 prajurit jerman tewas dan 33.000 prajurit menjadi tawanan perang. Perang ini pun berakhir karena pasukan Jerman sudah terdesak dan akhirnya mundur total dari peperangan. Akhirnya pada tanggal 14 November 1918 Jenderal dari Jerman Paul Von Lettow-Vorbeck menyatakan menyerah kepada Sekutu di Sungai Cambeshi, Zambia. Jenderal Paul sebenarnya berhasil memimpin pasukan pertempuran selama empat tahun dan tidak terkalahkan. Namun karena kondisi politik di Jerman sudah kalah telak maka otoritas Jerman memerintahkan Jenderal Paul untuk menyerah (Arifian, 2020). Jerman kalah dalam pertempuran begitupun negara-negara blok sentral yang lain sehingga diadakan Konferensi Damai di Paris. 
Konferensi Damai Paris dibuka di Istana Versailles, Prancis pada tanggal 18 Januari 1919. Para delegasi mengusulkan untuk membentuk Liga Bangsa Bangsa (LBB) yang nantinya sebagai organisasi dalam menyelesaikan konflik-konflik Internasional. Big Four dan para pemimpin yang telah kalah dari perang dunia 1 berkumpul di Hall of Mirror, Istana Versailles. Hal ini dilakukan bagi negara anggota Blok Sekutu dan Blok sentral yang terlibat dalam perang untuk melakukan negoisasi perdamian. Salah satu penjanjian yang terbentuk adalah Perjanjian Versailles. Perjanjian Versailles merupakan perjanjian antara Sekutu dengan Jerman. Perjanjian ini di harapkan mampu menstabilkan ekonomi dan politik di Eropa. Perjanjian ini sepakati bersama agar tidak ada penumbahan darah akibat peperangan. Namun ternyata Perjanjian Versailles ini di buat oleh pihak sekutu untuk menghukum Jerman. Jerman tidak diberi kesempatan untuk ikut bernegoisasi. Banyak warga Jerman yang tidak setuju dengan isi perjanjian itu. Awalnya pemerintah Jerman tidak menyetujui karena di anggap tidak adil dan mundur dari meja perundingan. Namun Sekutu menyatakan bahwa jika Jerman tidak mendatangani perjanjian tersebut maka perang akan berlanjut. Jerman tidak memiliki pilihan lain karena militer Jerman sudah hancur dan tidak mungkin untuk melanjutkan perang (Arifian, 2020)

Kepala pemerintah Jerman yang baru bermana Gustav Bauer mengirimkan telegram yang menyatakan bahwa bersedia untuk mendatangani perjanjian jika pasal-pasal tertentu ditarik. Kemudian sekutu memberikan waktu 24 jam kepada Jerman untuk menerima perjanjian atau menghadap pasukan sekutu di Rhine. Akhirnya Bauer menyerah dan mengirim telegram yang kedua dan menyatakan bahwa delegasi Jerman akan datang untuk mendatangani perjanjian tersebut. Sehingga pada tanggal 28 Juni 1919 perjanjian Versailles resmi di tanda tangani. Jerman sempat mundur dari meja perundingan karena isi perjanjian Versailles menyatakan bahwa Jerman harus menanggung ganti rugi atas terjadinya perang dunia 1. Jerman juga harus menyerahkan sebagian wilayahnya dan militer Jerman dibatasi (Khalid, 2014). Sekutu memiliki tujuan khusus dalam perjanjian Versailles ini. Tujuan Prancis adalah ingin melemahkan Jerman dalam bidang politik, ekonomi, militer,dan teritorial sehingga menjamin keamanan Prancis, selain itu Prancis juga ingin menggantikan Jerman sebagai produsen baja di Eropa. Prancis juga mengalami kehancuran fasilitas seperti pabrik dan rel kereta sehingga Jerman yang harus membayar akibat kehancuran tersebut. Tujuan Inggris adalah mendapat reparansi dari Jerman. Selain itu beberapa daerah teritorial Jerman akan di serahkan kepada Inggris. Tujuan Amerika adalah membentuk organisasi untuk menangani konflik-konflik internasional dan terbentuklah LBB (Thomas, 2007). 
Tokoh dari perjanjian Versailles (Big Four) yaitu; 1) David Lloyd George, perdana Mentri dari Inggris raya. Dia adalah seorang politisi yang ingin mendapatkan dukungan untuk sukses dalam pemilu. Secara pribadi Lloyd George merasa prihatin terhadap kebangkitan komunisme di Rusia. Sehingga dia takut jika nanti komunisme menyebar ke Eropa Barat. Setelah perang dunia selesai, Lloyd George merasa bahwa komunisme yang menyebar akan menjadi ancaman yang jauh lebih berbahaya bagi dunia. Lloyd merasa Jerman harus di rawat sehingga menjadi penghalang untuk melawan penyebaran komunisme, karena Lloyd tidak ingin Jerman merasa kecewa dengan pemerintahan dan beralih ke komunisme. Lloyd masih tetap menghukum Jerman namun tidak membuat Jerman sampai miskin. 2) George Clemenceau, perdana menteri Prancis, George memiliki keinginan agar Jerman berlekuk lutut terhadap Prancis dan tidak akan pernah memulai perang kembali. 3) Vittorio Orlando, perdana menteri Italia. Italia seharusnya menjadi blok Jerman dan Austria karena sudah mendatangani perjanjian Triple Alliance dimana jika ada salah satu dari ketiga negara tersebut di serang maka dua negara harus ikut membantu. Namun ternyata Italia tidak ikut sisi Jerman tetapi menunggu sampai tahun 1915 dan bergabung dengan Inggris dan Prancis. Italia ingin mencari wilayah kekuasan. 4) Woodrow Wilson, presiden Amerika Serikat. Wilson membuat proposal perdamaian pasca perang yang di kenal dengan fourteenth poin yang kemudian mengarah pada penciptaan Liga Bangsa-Bangsa. Wilson mengembangkan gagasan untuk membentuk liga bangsa-bangsa. Wilson meyakini jika perdamaian yang kekal dapat terwujud dengan adanya hukum, keadilan, dan kesepakatan yang adil antar bangsa (Morgenthau \& Thompson, 2010).

\section{Isi Perjanjian Versailles}

Dalam isi perjanjian Versailles Jerman harus menerima tanggung jawab penuh atas terjadinya perang dunia I. Isi perjanjian menurut (Miya, 2018) sebagai berikut:

1) Wilayah :

a) Di Eropa, Jerman harus menyerahkan wilayahnya kepada negara tetangga. Alsace Lorraine diberikan kepada Prancis, Northren Schleswig diberikan kepada Denmark, Eupen dan malmedy diberikan kepada Belgia, Hultchin diberikan kepada Cekoslowakia Pruasia Barat, Posen, Silesia diberikan kepada Polandia, Daerah Saar di bawah kendali LBB dalam kurun 15 tahun dan kemudian rakyat disuruh memilih untuk bergabung dengan Jerman atau Prancis, Memel dan Danzig berada di bawah kendali Liga Bangsa-Bangsa dan penduduk di wilayah ini diberikan izin untuk tetap tinggal di Jerman atau tidak untuk ferendum mendatang

b) Di Afrika, Jerman menyerahkan Afrika timur, Kamerun, dan Togo kepada Inggris, sedangkan Afrika barat Daya di berikan kepada Afrika Selatan. 
c) Di Asia-Pasifik, jajahan Jerman di Pasifik di serahkan kepada New Zealand dan Australia, kemudian menyerahkan hak sewa atas Kiauchow Shatung kepada Jepang.

2) Militer :

a) Jumlah kekuatan militer Jerman di batasi maksimal 100.000 orang

b) Angkatan laut Jerman maksimal 15.000 orang

c) Angkatan laut dibatasi yang hanya boleh memiliki kapal perang sebanyak 24 yaitu terdiri dari kapal perang gerak cepat maksimal 6, kapal perang bersenjata maksimal 6,kapal penghancur maksimal 12

d) Jerman di larang memiliki satupun kapal selam

e) Jerman wajib menghancurkan benteng-benteng pertahanannya

3) Ekonomi

Jerman bertanggung jawab penuh atas terjadinya perang dunia I sehingga harus membayar ganti rugi dari kerusakan infrastruktur akibat peperangan. Jerman harus membayar 135 milyar mark kepada sekutu. Reparansi dibayar dengan ansuran rutin kepada sekutu. Jerman kehilangan wilayah industri penting yang membuat kerugian ekonomi yang besar. Jerman juga di larang untuk bekerjasama dengan Austria dalam membentuk satu negara Superstate untuk menjaga potensi ekonominya.

Isi perjanjian Versailles ini memiliki kelemahan karena yang seharusnya menciptakan perdamaian justru menimbulkan benih-benih konflik. Pertama isi perjanjian tersebut menghina dan merendahkan Jerman, karena Jerman harus mengakui kepada dunia bahwa Jerman lah yang memiliki tanggung jawab penuh terhadap terjadinya perang. Meskipun Jerman ikut peran dalam perang, namun negara-negara Eropa lainnya juga bersalah karena telah memprovokasi Jerman. Kedua, Jerman mengganti kerugian perang kepada negara- negara sekutu. Jumlah ganti rugi tersebut sangat lah besar. Wilayah koloni Jerman di Asia dan Afrika juga diserahkan kepada sekutu. Padahal jumlah lahan koloni yang diberikan melebihi jumlah ganti rugi perang. Ketiga, Rusia perang selama tiga tahun dan bergabung dengan sekutu, Rusia menderita kerugian lebih besar dibandingkan negara anggota yang lain. Namun Rusia tidak di ikutkan kedalam Paris Peace Conference (terdiri dari para pemimpin negara-negara Blok Sekutu) hal ini dilakukan dengan alasan bahwa Rusia telah dipegang oleh komunis. Sehingga hanya Rusialah yang tidak ikut serta didalam perundingan. Perjanjian Versailles dianggap tidak adil oleh sebagian negara sehingga ketidakadilan ini memicu terjadi konflik baru (Arifian, 2020).

\section{Pengaruh Perjanjian Versailles}

Perjanjian Versailles membawa pengaruh yang besar terutama terhadap Jerman. Sebelum terjadinya perjanjian Versailles negara Jerman berbentuk Kekaisaran. Namun tokoh negara 
pemenang yaitu presiden Woodro Wilson mau menerima permohonan damai kepada pemerintahan yang demokratik. Hal ini dilakukan karena dia ingin berhadapan dengan seluruh rakyat Jerman bukan hanya dari penguasa saja. Sehingga Jerman yang awalnya berbentuk negara Kekaisaran berubah menjadi negara Republik. Karena tentara Jerman sudah hancur waktu itu maka Kaiser Wilhelm II terpaksa turun tahta. Kemudian partai-partai sosial demokratik mulai memproklamasikan bahwa telah berganti menjadi Republik. Perubahan pemerintahan di Jerman ini di lakukan agar dapat melakukan perjanjian damai terhadap Sekutu dan peperangan dapat dihentikan. Namun isi perjanjian Versailles ini di anggap menyakitkan bagi Jerman, karena perjanjian tersebut di buat oleh pihak Sekutu. Jerman tidak diberikan kesempatan untuk bernegoisasi tentang isi perjanjian. Hal ini dipergunakan oleh pihak sekutu untuk menghukum Jerman. Kondisi perekonomian Jerman menjadi sangat terpuruk. Industriindustri milik Jerman hancur. Pemerintah Jerman juga wajib mengganti kerugian yang cukup besar sebesar 132 Miliar mark kepada sekutu. Sehingga hal tersebut mengakibatkan tingkat pengangguran di Jerman meningkat $24 \%$ dan lebih dari enam juta orang yang menganggur. Jerman mengalami inflasi yang cukup tinggi. Terjadi pertimbangan strata sosial antara kelas atas dengan kelas menengah ke bawah. Pemerintah banyak melakukan korupsi dan masyarakat kekurangan makanan bergizi (Ramadhan et al., 2017). Jerman harus mengansur reparansi yang sudah di tetapkan dalam perjanjian Versailles.

Prancis sempat menduduki wilayah Ruhr pusat industri milik Jerman. Hal ini dilakukan Prancis karena Jerman tidak dapat memberikan reparansi yang diminta. Jerman memberikan hasil alam kepada Prancis seperti batu bara dan kayu. Sehingga pemerintah menyerukan kepada rakyat Jerman untuk melakukan perlawanan pasif terhadap Prancis. Penduduk Ruhr seperti penambang batu bara dan pekerja kereta api berhenti bekerja dan tidak akan mematuhi perintah dari Prancis. Sehingga produksi dan transportasi dihentikan. Namun hal ini membuat keuangan Jerman tidak ada pemasukan, selain itu pemerintah juga harus membayar gaji para karyawan dan buruh termasuk memberikan uang kepada penjabat Runh yang berhenti bekerja karena telah dipecat Prancis. Akhirnya Jerman membatalkan perlawanan pasifnya. Kemudian Jerman mencetak jutaan mata uang Mark, sehingga hal ini semakin membuat nilai mata uang Mark merosot tajam. Hiperinflasi ini membuat keuangan publik Jerman menjadi hancur (Morgenthau \& Thompson, 2010)

Selain dampak yang dialami oleh Jerman. perjanjian Versailles ini juga berdampak terhadap kekuatan ekonomi yang berhasil dikuasai AS. Isi dari perjanjian Versailles turut membangkrutkan Eropa. Meskipun yang menanggung kerugian adalah Jerman. Namun hal ini turut menyeret dan menggocang ekonomi Eropa. Eropa kehilangan posisi penting secara 
ekonomi, kurang lebih 500 tahun Eropa menjadi bangsa imperialis dan kolonialis. Sehingga posisi tersebut digantikan oleh Amerika Serikat sebagai raksasa ekonomi yang baru. Amerika menjadi kreditor nomer satu dengan memberikan pinjaman finansial dan menjadi negara produsen terbesar lantaran sumber daya Eropa sudah terkuras habis. Setelah perang selesai negara-negara di Eropa mengalami kebangkrutan sehingga membutuhkan bantuan finansial. Amerika berada pada posisi yang strategis sehingga mampu meminjamkan dengan sistem bunga. Sehingga Amerika serikat mampu menguasai kekuatan ekonomi. Perjanjian Versailles juga mengakibatkan banyak negara-negara baru bermunculan. Negara-negara tersebut diberikan kebebasan untuk berpisah dengan Jerman atau menentukan nasibnya sendiri (Arifian, 2020)

\section{Pelanggaran Jerman terhadap Perjanjian Versailles}

Disetujuinya perjanjian Versailles menyebabkan reaksi dari rakyat Jerman termasuk Adolf Hitler. Adolf Hitler marah saat Jerman menyerah dalam perjanjian Versailles, ia merasa orang-orang Yahudi dan komunis telah mengkhianati dan menghancurkan bangsanya. Adolf Hitler bergabung dengan Partai Buruh Jerman, yang nantinya partai ini berubah menjadi Partai Buruh Nasionalis, NSDAP (Nationalsocialistische Deutsche Arbertei Partei) yang lebih di kenal dengan nama Nazi. Partai ini kemudian di populerkan oleh Hitler dengan menonjolkan rasa nasionalisme. Kesengsaraan rakyat akibat perjanjian Versailles ini segera dimanfaatkan oleh Hitler dan partainya untuk memprovokasi rakyat. Hitler mengatakan kepada rakyat jika terpilih menjadi pemimpin maka akan menghancurkan perjanjian Versailles. Menurut Hitler, yang membuat Jerman hancur adalah para penanda tangan perjanjian Versailles. Segala kesengsaraan yang di alami Jerman akibat dari kaum Yahudi dan Komunis, sehingga harus dilenyapkan dari Jerman. Hitler meyakini bahwa ras Jerman adalah ras Arya yang paling unggul di dunia (Zazuli, 2009). Kepawaian Adolf Hitler dalam berpidato membuat partainya mampu mengungguli partai-partai yang lain. Hitler menyingkirkan saingannya partainya dengan berbagai cara. Hitler menyusun politiknya dengan cara diktator. Kaum anti Nazi pun dilenyapkan, sehingga Hitler menjadi penguasa tunggal di Jerman. Dunia mengalami Depresi yang besar sehingga membuat rakyat Jerman semakin menderita. Pengangguran semakin bertambah dan inflasi tidak dapat dihentikan. Rakyat bosan dengan demokrasi ala Weimar yang tidak bisa berbuat apa-apa. Sehingga rakyat membutuhkan pemimpin baru untuk membebaskan rakyat Jerman dari penderitaan dan cengkraman sekutu. Partai Nazi akhirnya menang dalam pemilu dan Hilter berhasil menjadi pemimpin. Jerman di bawah kekuasaan Hitler beransur-arus bangkit dan menjadi negara kuat. Hitler adalah orang yang pemberani dan pandai mengatur 
bidang ekonomi. Sehingga Jerman berhasil membuat perekonomiannya membaik. Renzim Nazi membuat perekonomian stabil dan mampu menekan angka pengangguran (Octavania, 2015).

Hitler berambisi untuk dapat menguasai Eropa dan dunia sehingga membuat Jerman kembali berhadapan dengan negara-negara kuat di Eropa. Tanpa memperdulikan perjanjian Versailles perlombaan kekuatan baru pun dimulai, Hilter mulai membangun kekuatan militernya secara besar-besaran. Jerman juga berambisi untuk membangun infrastruktur untuk mengimbangi negara-negara di Eropa. Jerman menciptakan tank-tank modern dan memproduksi ribuan parzer. Pada tahun 1939 kapal perang modern milik Nazi diluncurkan. Hal ini merupakan pelanggaran terhadap perjanjian Versailles. Namun saat itu Inggris dan Prancis mengalami depresi ekonomi sehingga sibuk untuk memperbaiki ekonominya sendiri (Lakmono, 2014). Perjanjian Versailles ini juga merupakan faktor terjadinya perang dunia II, dimana masyarakat Jerman masih memiliki dendam akibat kekalahan. Isi perjanjian Versailles membuat Jerman harus menanggung semua penderitaan, sehingga ingin membalaskan dendam kepada Inggris dan Prancis. Kekuatan Nazi Jerman dan Hilter semakin kuat karena menggerakkan kaum nasionalis. Partai nasionalis menolak untuk memenuhi perjanjian Versailles. Wilayah-wilayah Jerman yang dulu diambil karena perjanjian Versailles di rebut kembali oleh Hitler. Hilter mengumumkan program pembangunan persenjataan, pada tahun 1936 Hilter memerintahkan pasukan militer jerman untuk menempati daerah Rheinland yang sebenarnya merupakan daerah bebas militer. Hal ini tentunya bertentangan dengan perjanjian Versailles. Hitler menginginkan daerah Danzig, Polandia untuk diserahkan kepada Jerman. Polandia tidak hanya di incar Jerman tetapi di incar juga oleh Uni Soviet. Sehingga Jerman dan Uni Soviet melakukan perjanjian damai untuk pembagian wilayah Polandia. Setelah perjanjian tersebut Jerman memberikan peringatan terakhir kepada Polandia untuk menyerahkan kota Danzig namun Polandia menolak. Jerman pun akhirnya menyerang Polandia Barat. Inggris dan Prancis yang menjamin kedaulatan Polandia akhirnya menyatakan perang terhadap Jerman (Octavania, 2015).

\section{KESIMPULAN}

Perjanjian Versailles adalah perjanjian antara Sekutu dengan Jerman setelah terjadinya perang dunia I. Perjanjian ini awalnya disusun sebagai jalan perdamaian. Namun perjanjian ini dimanfaatkan dan dibuat oleh sekutu untuk menghukum Jerman. Hal ini disebabkan karena Jerman adalah negara dalam blok sentral yang memiliki kekuatan paling tinggi. Negara-negara Sekutu mengalami kehancuran fasilitas dan mengalami banyak kerugian dalam perang karena untuk melawan kekuatan dari Jerman. Perjanjian Versailles disusun oleh Negara Sekutu yaitu 
Prancis, Inggris, Italia, dan Amerika Serikat yang memiliki keinginan untuk membalas dendam kepada Jerman dengan membuat perjanjian secara sepihak. Isi perjanjian Versailles menjelaskan bahwa Jerman harus bertanggung jawab penuh atas terjadinya perang. Sehingga Jerman wajib membayar ganti rugi peperangan, menyerahkan wilayah kekuasaanya, serta militernya dibatasi. Jerman tidak diberikan hak untuk bernegoisasi. Pengaruh perjanjian ini mengakibatkan Jerman harus kehilangan industri-industrinya dan mengalami krisis ekonomi, angka pengangguran meningkat dan terjadi pertimpangan strata sosial. Hal ini mengakibatkan Jerman mengalami banyak kerugian dan memutuskan untuk keluar dari Perjanjian Versailles.

\section{DAFTAR PUSTAKA}

Arifian, A. (2020). Sejarah Lengkap Perang Dunia I : 1914-1918. Anak Hebat Indonesia.

Bangun, B. H. (2017). Konsepsi Dan Pengelolaan Wilayah Perbatasan Negara: Perspektif Hukum Internasional. Tanjung Law Journal, 1(1), 56. https://doi.org/2541-0490

Khalid, M. (2014). Treaty of Versailles. https://liberalarts.utexas.edu/europeanstudies

Lakmono, E. (2014). Imperium III : Zaman Kebangkitan Besar. PT Mizan Publika.

Miya, A. (2018). Perjanjian Versailles Terhadap Perkembangan Hukum Internasional. https://academia.edu/37079954/perjanjian_versailles_p\%0Aterhadap_perkembangan_hu kum_internasional\%0A

Morgenthau, H. J., \& Thompson, K. W. (2010). Politik Antarbangsa (terjemahan Maimoen, S., Fatwan, A.M., Sudradjat C.). Yayasan Pustaka Obor Indonesia.

Octavania, V. (2015). Jerman di Bawah Pemerintahan Adolf Hitler (Kajian Historis Gerakan Oposisi Terhadap Pemerintahan Adolf Hitler Pada Tahun 1933-1945). Skripsi. Universitas Pendidikan Indonesia.

Putra, R. P. (2018). Penyebab Perang Dunia I Dalam Perspektif Jerman. https://doi.org/10.13140/RG.2.2.31496.93443

Ramadhan, D., Darmawan, W., \& Iriyadi, A. (2017). Hjalmar Schacht, Sang Diktator Perekonomian Jerman (Sebuah Tinjauan Historis). FACTUM: Jurnal Sejarah Dan Pendidikan Sejarah, 6(1).

Sarsito, T. (2009). Perang dalam Tata Kehidupan Antarbangsa. Jurnal Komunikasi Massa, 2(2), $112-116$.

Thomas, J. (2007). Negotiate To Win : 21 Jurus Ampuh Untuk Menangkan Negoisasi. Gramedia Pustaka Utama.

Zazuli, M. (2009). 60 Tokoh Dunia Sepanjang Masa. Narasi. 